exposing hersclf to too much danger, she never failed to give an angry bite to her unsuspecting rival, and immediately to rush for shelter under a kneading-trough, from which position my greyhound was unable to dislodge her.

After a short time the spaniel had puppies, and she was placed with two of them in a corn-loft, over the kitchen, from which there was a door which led to it by a flight of stairs ; the door was usually kept closed in consequence of the known animosity between the two rivals. For some days the new mother, entirely occupicd with the care of her little ones, did not descend to the kitchen, and my greyhound occasionally showed a strong desire to go up to the loft and sce what was going on there. When the puppies were about seven or eight days old, their mother besan to re-appear in the kitchen, and to observe towards the greyhound the same line of conduct, with the exception only of an appearance of increased hatred. At length, on one occasion, when the spaniel was eating her dinner, and the corn-loft door happened to be partly open, my greyhound, taking advantage of the opportunity, sprang up the stairs of the loft. I observed the circumstance, and on calling her down she immediately obeyed, and made her appearance before me with a look of perfect satisfaction. About an hour afterwards my aunt's husband, on going to the loft, found both the puppies dead, without the least mark of external violence, and he was at a loss to imagine what could have caused their death. For myself I had an impression on my own mind as to the cause of death, but I did not consider it neces. sary at the time to mention it to others. I opened the bodies of the puppies, and found my opinion confirmed. The skin was externally sound through its elasticity, but the fangs of the greyhound had done their work, and the liver had been bruised into a kind of marmalade-exactly in the same manner as the greyhound usually crushes the liver of the hare or the rabbit, which, literally speaking, are no sooner seized than dead.

In November last, when I was staying with my cousin, I was much interested in observing the proceedings of various kinds of poultry in a field almost contiguous to the house. There were six or seven young guinca fowls, ducks, hens, \&c., and also a pair of old guinea fowls, which kept always by themselves, and continued running to and fro with that perpetual restlessness which is natural to them. In the midst, however, of their wildest proccedings they always appeared to keep an eye on the young guinea fowls, and whenever any of the other poultry happened to approach the spot where they were, the old guinea fowls invariably ran with all speed and drove them away. Two large hens alone seemed to be exempt from this rough treatment, and to have full permission to come near the young guinea fowls or not, just as they liked. One of the hens, in particular, seemed to cnjoy some special privileges, and in case of any apparent danger, there was some immediate proof of care and protection on the part of the old guinea fowls.

'The above circumstances excited my curiosity, and I obtained the following explanation :-

One of these hens had hatched some guinea fowls' eggs, but after three days had neglected to perform the new functions incumbent on her, and had left the young brood'to themselves. Fortunately, the other hen, which had previously exhibited the well-known symptoms of the fever of incubation, adopted the deserted young ones, and had nursed them with the greatcst affection till they were able to take care of themselves. The old guinea fowls, it appears, had observed all these circumstances, and had retaincd a grateful recollection of them.

Under the roof of a small tower at my father's house in the country, a large number of sparrows (consulting their own convenience, rather than that of others), had established their nests; but in consequence of the extensive injury caused to the corn-fields by their depredations at harvest-time, my father, with a view to lessen their num- ber, gave direction that all the nests should be removed, and thus, by this wholesale order of clestruction, about 80 nests with 366 egrgs suddenly disappeared. Their fondest hopes being thus blighted, and the expected fruit of all their labour nipped, as it were, in the bud, the sparrows bctool themselves to noisy meetings, and, in their own way, to expressions of anger and resentment. This proceeding continued for at least a week, after which they dispersed, and went in search of some other less dangerous shelter for their future progeny. In the following year some sparrows, which had built their nests under other buildings of our country house, and which had been left unmolested, returned to them; but from that time to the present day (forty-cight years) I can safely affirm that no sparrow has ever rebuilt her nest under the roof of the tower. The singular facts of the case are these: the sparrows decidedly object and decline to build any more nests under the roof of the tower, but they are quite willing to avail themselves of the shelter of the position during the severe nights of the winter season.

Montpellier

DR. PALADILhe

\section{THE GROWTH OF SALMON}

SINCE the time of Magna Charta it has been an object, directly or indirectly, on the part of the Legisfature, to protect the supplies of salmon with which our rivers used to be so abundantly stocked: but notwithstanding the laws which have at various times been enacted, this fish gradually became scarcer till, in $186 \mathrm{r}$, all the old laws were repealed, and fresh and more stringent regulations made for protecting and increasing our salmon supplies. In addition to the fostering care which is bestowed, under the Salmon Fishery Acts of 1861 and 1865 , on the fish in the rivers, means have bcen adopted to artificially rear salmon, so as to increase their numbers more rapidly than could be done in the ordinary course of nature. Mr. Frank Buckland has been the pioneer of this system of artificial breeding of salmon and trout, and the experiments and operations which have been carried on during the last few years have thrown great light on the hitherto unknown habits of this "king of fish."

Anyone who looks into the fishmongers'shops just now can see what a clean, fresh-run salmon, ready for cooking, is like-a silvery, plump creature, whose "lines" are made for speed in water, and whose graceful curves give the completest idea of vigour and strength in stemming a rapid current of water.

But very few people, probably, know what sort of an appearance this beautiful fish presents in its infancy. Hidden away during that period in the upper waters of our salmon rivers, and ultimately in the depths of the sea, it is lost to sight till it grows large enough to be taken by the salmon nets; and until lately very little was known of its natural history, or of its habits, though the experience of the last few years has revealed many interesting facts concerning the development of this fish, through the egg, fry, smolt, and grilse stages, till it becomes a full-grown salmon.

Fig. I represents the egg-natural size-of a salmon just laid: Each female salmon carries, on an average, 800 to 900 of such eggs to every pound of her weight. They are generally of a pinky opal colour, elastic to the touch, covered with a soft homy membrane, with a minute opening through which a particle of the spawn-the soft roe- of the male fish enters, and the egg is fertilised. From this moment the young fish gradually develops, under the influence of the cold running water. At the end of about 35 days-more or less according to the temperature, which should be about $40^{\circ}$ - two little black specks can be seen, as at Fig. 2 , which are the eyes of the embryo fish; the vertebra may be discorned in the form of a faint red line, and a small red globule 
which shortly afterwards appears, represents the vital organs of the embryo fish.

At the end of about 80 to roo days from the deposition of the $e$ g the fish has so increased in size that it bursts the "sh ell" and makes its début in the form represented at Fig. 3. The sac or umbilical vesicle attached to the under part of the fish contains a secretion resembling albumen, which affords nourishment to the infant fish for the first six weeks or so of its existence. By that time it is quite absorbed, and for the first time we see a perfect

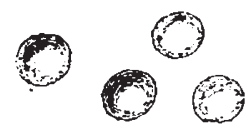

Fig. :

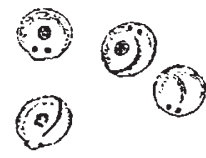

Fig. 2.
Fig. x.-New-2:d Salmon Rgg. Fig. 2,-Egg after about 35 days.

fish, Fig. 4, with its fins, gills, and scales, which have hitherto been present, but imperceptible except under the microscope, fully formed: and now the young salmon begins to feed. His growth is not very rapid for some months, the lines $a b c$ representing the average length of a salmon at 2,3 , and 4 months old. At 2 years old the fish is about 9 to 12 inches long.

As soon as they are large enough and strong enough, the "smolts," as they are now called, descend to the sea; here they are lost sight of until they return up the river as "grilse." The actual duration of their stay in the sea is not yet known, from one to three years being variously estimated as the probable length of time. The object of this migration to the sea is to find the food which is necessary for the secretion of the fat of the fish, who lives on the Infusoria, smaller fish and crustaceans, and the spawn of sea-fish which abound in our seas. The length of their stay in salt-water is regulated, no doubt, by various circumstances, and is not the same in every case. When the salmon has laid up a sufficient supply of fat in its body and on its pyloric appendages, which are a wonderful provision of Nature for the secretion of an amount of fat sufficient to supply it during its sojourn in fresh waters, it ascends the river, its roe or spawn developing as it ascends; till, about Christmas-time, or sometimes earlier, it reaches the shallow headstreams of the river, in the gravelly beds of which it deposits its egse, returning immediately afterwards to the sea, no

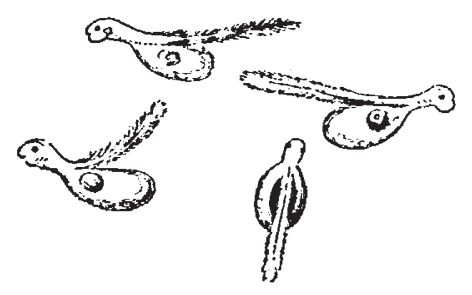

FIG 3.-Finh coming out of egg.

lorger in the bright, plump, muscular condition in which it ascended, but a lean, lank, ugly, wounded beast, which one would hardly recognise as Salmo salar. Fig. 5 represents the head of a "kelt," as those salmon are called which have newly spawned. The curved projection, or hook, on the lower jaw, is a cartilaginous membrane, the use of which nobody knows. The fish is in a very weakly condition, as his fat is gone, and he perhaps assumes this appearance to frighten other animals, which might otherwise be tempted to attack him. The drawing is taken from the photograph of a salmon, weighing 2olb., which was found dead on the banks of one of our Welsh rivers.
This fish, had it survived, would have returned to sea, recovered its fat, and presently come back worth $2 l$. or 3l., whereas, by dying in this condition, it was worth nothing. It had, however, done its duty by depositing perhaps 16,000 eggs. Only a very small percentage, however, of the eggs laid ever become adult fish. Floods wash them out of their gravel nests; ducks, and other birds, eat them; beetles and various insects attack them; they are smothered with mud, or left high and dry on the shore; the young fish are poisoned by pollu-
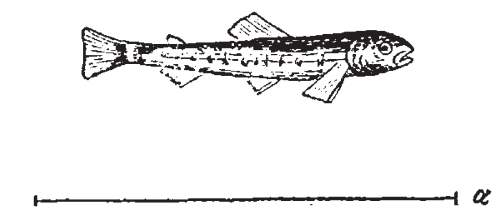

Fic. 4--Young Salmon six weeks old. $a, b, c$, size of salmon at two, three, and four months respectively.

tions, or diverted into mill leats and canals, and so lost; trout eat them wholesale; in fact the whole of their earliest existence is a very living death, and it is a wonder, with all the ordeals they have to pass through, that we have any salmon left. To kill them legitimately for food for ourselves is bad enough, and we ought to do all we can to protect them when young.

In the artificial system of breeding salmon the adult fish are caught just as they are on the spawning beds, and the eggs taken from them; the ova and milt are properly mixed together, and the eggs placed in troughs of water so arranged as to imitate as closely as possible the natural conditions necessary for the development and growth of the fish. Properly managed, 9o per cent. of the eggs will hatch out: the young fish are turned into the river when they are about a year old; if they can be kept two years in tanks large enough, with plenty of running water, so

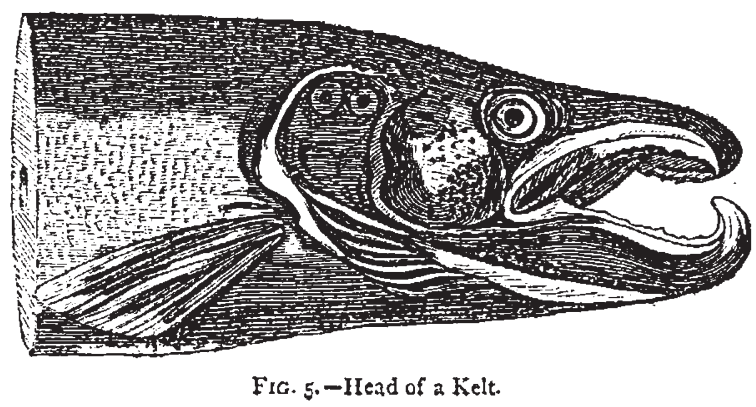

much the better for the prospect of their reaching the sea in safety.

When we can make up our minds to keep all our pollutions out of our rivers, and build "salmon ladders" over all the weirs, so as to give the fish a fair field, and enable them to run up stream unimpeded, then, and then only, shall we see salmon as plentiful throughout the country as it is said to have been in the North a century ago, when apprentices are reputed to have stipulated in their indentures that they should be fed on salmon not more than three days a week. Without this all our efforts to stock our barren rivers with artificially bred fry will prove comparatively unavailing. 